\title{
Distance E-Learning in the System of Professional Development of Corporation
} Managers: Challenges of COVID-19

\section{Ihor Bondar ${ }^{1 \bowtie(D)}$ Tatyana Gumenyuk² Yurii Horban ${ }^{3}$ \\ Olena Karakoz ${ }^{4}$ \\ Olena Chaikovska ${ }^{5}$}

${ }^{2,3,2,5}$ Kyiv National University of Culture and Arts, Ukraine. Email:bondar@iua

Email:gumenyukt@i.ua

"Email:y horban@fm.ua

Email:karakoz@i.ua

Email:chaikorska o@i.ua

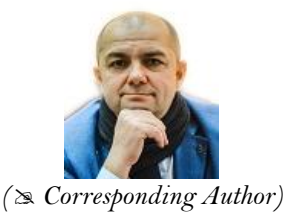

Abstract

The corporate education system is implemented through sequential and step-by-step in-company e-training based on integrity of goals, objectives, functions, learning technologies, and content structure of the training material, which add flexibility and vitality to the entire learning process with an advanced reflection of reality. The definition of a corporate training center in terms of a systematic approach is formulated as a system in which training and development of personnel are initiated and managed by the company itself, carried out within the company and involving internal resources. Thus, training and professional development of managers is not just an element of organizational practice or type of activity of certain employees of the organization, but a fully fledged part of the development strategy of the organization and the entire existing organizational system. To implement this process, modern transnational corporations (TNCs) create corporate training centers in which training and personnel development is initiated and managed by the company itself, carried out within the company and involve internal resources. The algorithm of creating a corporate training center covers a number of stages, in particular: support by the management; legal and financial support; creation of organizational and pedagogical conditions; program and content implementation support and practical application of the personnel training system; and a control and reporting system.

Keywords: Business education, Professional development, Corporate training center, Personnel training, E-learning.

Citation | Ihor Bondar; Tatyana Gumenyuk; Yurii Horban; Olena Karakoz; Olena Chaikovska (2020). Distance E-Learning in the System of Professional Development of Corporation Managers: Challenges of COVID-19. Journal of Education and e-Learning Research, 7(4): 456-463.

History:

Received: 9 July 2020

Revised: 28 October 2020

Accepted: 16 November 2020

Published: 7 December 2020

Licensed: This work is licensed under a Creative Commons

Attribution 3.0 License (c)

Publisher: Asian Online Journal Publishing Group
Acknowledgement: All authors contributed to the conception and design of Acknowled

Funding: This study received no specific financial support

Competing Interests: The authors declare that they have no conflict of interests.

Transparency: The authors confirm that the manuscript is an honest, accurate, and transparent account of the study reported; that no vital features of the study have been omitted, and that any discrepancies from the study as planned have been explained.

Ethical: This study follows all ethical practices during writing.

\section{Contents}

1. Introduction.

2. Literature Survey

4. Results 


\section{Contribution of this paper to the literature}

This study contributes to the existing literature on the corporate education system and is implemented through sequential step-by-step, in-company e-training based on integrity of goals, objectives, functions, learning technologies, and content structure of the training material, which add flexibility and vitality to the entire learning process with an advanced reflection of reality.

\section{Introduction}

With globalization transformation prevalent in societies globally, the need to develop human resources as the most valuable capital possessed by an organization has come to the fore. In this context, the problem of continuous professional development of personnel, covering formal, nonformal, and informal education, including basic and additional training, retraining and advanced training, and in-company training, as well as self-education and selfdevelopment, becomes especially relevant.

The issue of distance learning in corporations in the context of the COVID-19 pandemic is especially acute. It requires the development of new forms of learning based on the SMART approach, which allows development of the relevant skills, abilities, and competencies of managers.

Scientific search is specified by the professional development of managers because, as practice shows, the level of their professionalism, competence, and personal qualities depends on the effective activity of the organization as a whole and, in particular, its competitiveness in the market.

Statistics show (Akinbola, Solomon, \& Ibidunni, 2018) that 10\% of companies fail annually due to insufficient management training, resulting from either lack of financial support in training their own managers or hiring highly qualified professionals in the field.

A high level of professional qualification, along with a balanced and structured system for training and development of managers, plays a crucial role in the German management culture. Considering the costs of manager training as a strategic investment, transnational corporations are at the same time developing a system of measures aimed at retaining trained professionals. German managers have a high level of corporate loyalty: the average length of service in one organization is 8 years, while in the USA it is 3 years (Mizikaci, 2019).

The purpose of this research was to carry out a comprehensive scientific analysis of managers' professional development systems in transnational corporations in Germany and Poland on the basis of systemic, personally oriented, competence, process, and situational approaches; to identify constructive ideas of experience in these countries; and to substantiate the potential of their creative application in modernizing the system of professional education of managers.

\section{Literature Survey}

For the development of the conceptual, theoretical, and methodological foundations of the identified problem, a thorough analysis of the current state of its research in the philosophical, psychological, pedagogical, and socioeconomic achievements of scientists is important (Zhaoqun \& Haiqing, 2017).

Therefore, we consider it appropriate to carry out this analysis in the following areas: philosophical and conceptual foundations of personality development in the context of civilizational transformations (Jamali, Karam, \& Blowfield, 2017); fundamental provision of professional development in the system of continuing vocational education for adults, in accordance with the concept of lifelong learning (Chen, Xu, \& Zhai, 2019); conceptual principles of human resources development and knowledge management in accounting organizations (Drobyazko, Barwińska-Małajowicz, Ślusarczyk, Zavidna, \& Danylovych-Kropynnytska, 2019; Drobyazko, Okulich-Kazarin, Rogovyi, Goltvenko, \& Marova, 2019); organizational and pedagogical aspects of corporate/in-house training organization (Deering \& Sá, 2018); and methodological and didactic features of training, retraining, and advanced training of managers (Avidov-Ungar \& Reingold, 2018).

In general, the problem of professional and personal development of specialists is not new - throughout human history it has been, and still is, the subject of study by philosophers, scholars, educators, and practitioners (Milner, McCarthy, \& Milner, 2018).

Based on content analysis, we can distinguish components of the personnel professional development system in general and managers in particular, specifically:

(1) Basic professional education obtained in educational establishments (Rubens, Schoenfeld, Schaffer, \& Leah, 2018).

(2) In-house training (Boiral, Raineri, \& Talbot, 2018), subdivided into two main categories. The first of these includes short-term compulsory training, both at the enterprise and in specialized educational institutions, based on problem solving specific to an organization with the involvement of its own or outside teachers, which is a system of educational certification measures provided by the production system (Da COSTA, Pelissari, \& Gonzalez, 2018; Garber, 2017); schooling of young specialists aimed at their becoming acquainted with the specifics of the professional activity and traditions of the company; mentoring aimed at rapid and successful preparation for fulfillment of professional duties and learning traditions of the company; a production management school aimed at creating managerial competence in company managers; learning a foreign language; advanced training aimed at supporting the technological processes of a contemporary enterprise; and professional retraining aimed at keeping up to date with rapidly changing techniques and technologies.

(b) The second is additional training outside the company that is related to its strategic objectives and provides only additional education that a manager receives in accordance with the area of work in which the company plans to use it (Hilorme, Sokolova, Portna, Lysiak, \& Boretskaya (2019); Hilorme, Tkach, Dorenskyi, Katerna, \& Durmanov (2019); temporary rotation as a form of self-study in order to acquire new skills (used in companies requiring multi-professional competence); professional retraining with an additional qualification conferred, "manager in a specific area"; Master of Business Administration (MBA) and Executive MBA for senior executives and reserve personnel. 
(3) Long-term compulsory education of managers, which encompasses a second higher education course, resulting from requirements of the company due to the irrelevance of the first higher education course to the company profile (Gunawan, Aungsuroch, \& Fisher, 2018).

(4) Post-professional education of managers, which differs from the previous system in that it does not necessarily have to be systematic and may have nothing to do with the strategic tasks of the company (postgraduate, doctoral, business education) (Padley et al., 2019).

(5) Post-study support (Kangas et al., 2018) covering: organization and coordination of production, innovation, inventive, scientific, and creative activity of young professionals; organization and holding of in-house thematic scientific and technical exhibitions; participation during in-company conferences; individual counseling and coaching; organization of communities on professional interests, etc.

(6) Self-education and self-development (Choi, Kim, \& Kim, 2018).

\section{Methods}

The concept of the study is based on the provision that the professional development of managers as a purposeful process, covering a set of interrelated components and having a continuous and adaptive nature, gains efficiency and effectiveness under conditions of a systematic approach to its organization, and implementation of a holistic analysis of interacting mechanisms related to theoretical and methodological, psychological and pedagogical, programmatic-methodological, legislative, and regulatory support.

Implementation of this idea is ensured by three interrelated concepts: (1) theoretical and methodological, substantiating a comprehensive methodological complex of approaches that cover systematic and closely related synergistic; personality oriented, the semantic field of which expands and specifies directly related culturological with acmeological and axiological components, and indirectly related subject-subjective and sociologicalmanagerial, as well as competence, process and situational. (2) Theoretical, taking into account the leading theories, concepts, and models of personnel management, initially from the standpoint of situational and process approaches, providing for separation of components, stages, content, and identification of features of the professional development of managers in the corporate education system. (3) Practically oriented, aimed at revealing constructive ideas from the experience of developed countries, and their creative application in the scenario of Ukrainian reality.

\section{Results}

The professional qualification of a specialist requires the knowledge and skills necessary to performing a particular job, and it is always confirmed by a relevant document. We identify four types of professional qualification: beyond professional qualification - the basic requirements necessary in any job, both professional and non-professional (e.g. social); general professional qualification characteristic of a particular professional field, on which a group of professions is usually based; basic professional qualification - applies to a specific profession and covers the basic skills necessary to perform tasks effectively; and specialized qualification - additional skills specific to a particular profession, which are determined by professional specialization or special types of work.

Competences, unlike specialized knowledge and professional skills, are the basis of effective activity in various positions. The modern system of work mostly appreciates those competencies in the work of a manager that contribute to realization of professional tasks. Among these, and in prime position, is the ability to effectively perform professional duties in accordance with the standards of the position, which provides for a certain range of profession-specific knowledge, abilities, and psychophysiological characteristics that a specialist should possess.

It should be emphasized that, in the context of our study, the notion of professional competence is broader than that of professional qualification because it covers both the qualification required for the pursuit of professional activity and the ability to adapt to new conditions, which requires self-initiative and participation and provides effective actions. In addition, efficiency is the sign of competencies that differentiates them from qualifications.

Among a number of competencies, Polish and German scientists have identified the following categories:

1. Competencies that are related to the employee's potential, opportunities for its development, and the use of abilities in order to obtain the latest qualities of personnel in accordance with the requirements of the workplace in the company.

2. Competencies related to skills and abilities required to accomplish a particular job. These include communication competencies, intellectual, interpersonal, organizational, technical, business, leadership qualities, self-organization, etc.

3. Knowledge-related competencies that are necessary to accomplishing specific tasks within a profession, specialty, or position within an organization. This category includes competencies that describe the level of knowledge that an employee should possess and can apply in their respective situation. Knowledge can relate to facts, events, rules, and theory.

4. Competencies related to activity styles describing personal characteristics such as orientation on social issues, collaboration orientation, and goal achievement.

5. Competencies related to principles and values relating to rules, values, and beliefs that allow identification of the motives of activities linked to to work-related expectations, and to life roles that influence choice.

6. Interest-based competencies providing benefits in terms of tasks, types of work, and working conditions in particular, those affecting performance when professional activities are completely aligned with supraprofessional interests.

7. Physical competencies refer to skills related to physical requirements in the workplace; these are divided into three groups: physical abilities, sensory perceptions, and psychophysiological features.

Considering the subject of our study, we will add one further item to this list:

8. Management competencies are qualities necessary for the effective performance of management functions when managing structural units and/or processes. In particular, management competencies ensure the practical ability to manage production, individual business processes, and business as a whole. They are relatively versatile because they are necessary for all brunches and spheres of production. 
Thus, from the perspective of our research, the functional capabilities of the modern model of corporate competencies should be oriented towards solving the widest range of tasks not only in the field of selection but also in the sphere of professional development of management personnel. In this regard, the managerial competency model, along with personal psychological characteristics, should include basic managerial skills that significantly influence the quality in performing job duties and the overall effectiveness of the management process at different levels of the organizational hierarchy.

Development and application of this model are relevant to TNCs, which have specific functions such as integration of large amounts of resources (including labor), of several activities into a single technological cycle, and of significant geographical distances separating production facilities.

Scientific research conducted on the analysis of competencies of managers showed that the source of professional success was primarily the sociopsychological competencies and personal qualities of management.

The results from analysis of typical attributes of the activity of international business managers, and generalization of competencies characteristic of each of them necessary to achieving success, enable the creation of models of key competences for each category of TNC manager (Figure 1).

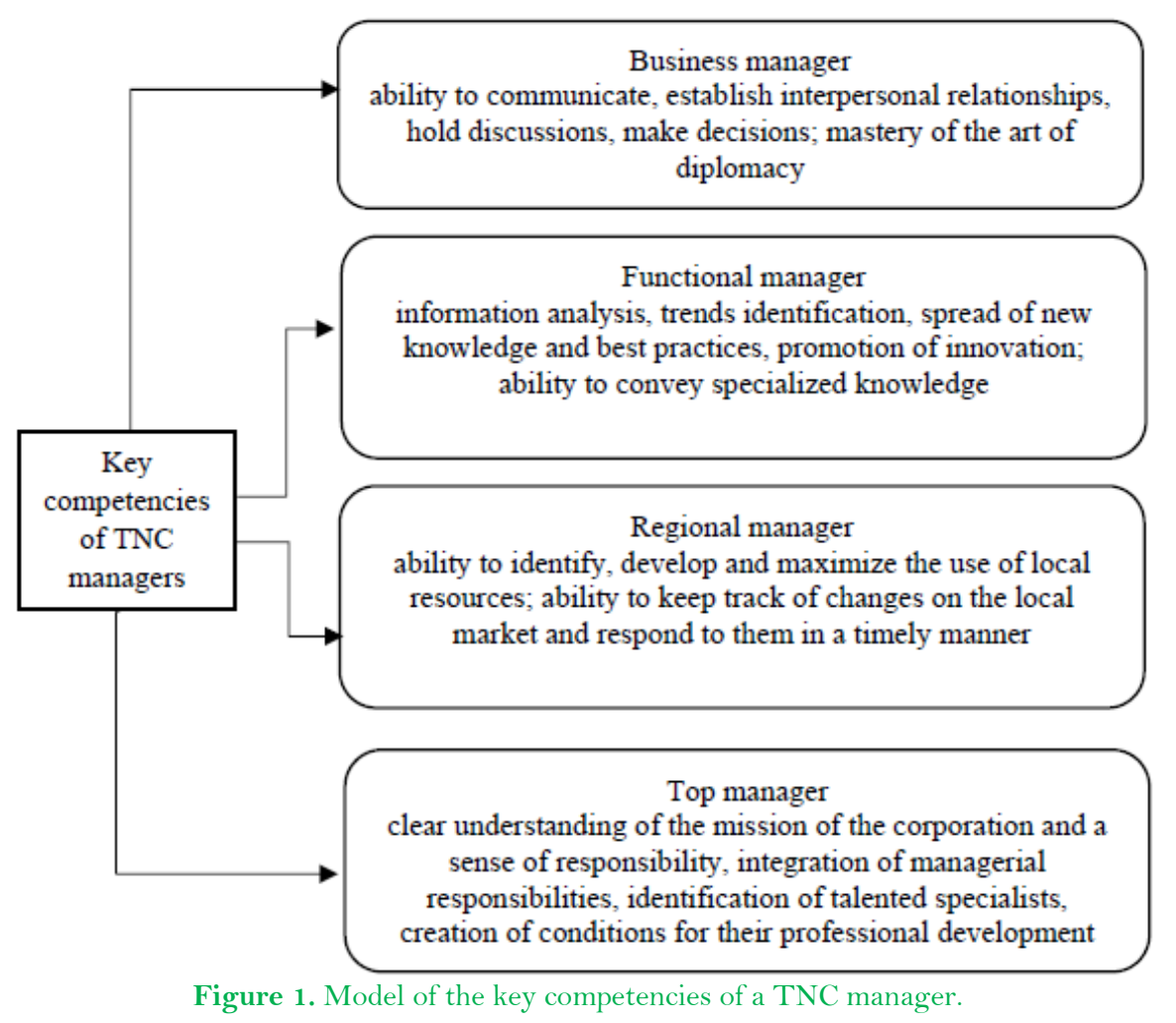

Thus, it can be summarized that employers in the process of selection of managers increasingly refuse to put forward qualification requirements and look for specialists with the specific competencies they need.

Therefore, each transnational corporation can now be regarded as a learning organization - that is, a kind of educational institution that, on the one hand, provides employment and, on the other, provides its employees with the necessary educational opportunities for their professional development.

In order to effectively transfer these intangible assets, companies set up their own training centers with the purpose of creating a supportive learning environment in which all employees can develop both professionally and personally. Obviously, to implement such a large-scale activity a single specialist in the training department is not sufficient.

It is necessary to create a separate structure with its mission, goals and objectives, and regulatory framework. The functions of this structure can be implemented through an in-house training center whose mission is to form and develop systematic personnel training that will result in enhancement of the company's competitiveness. Therefore, we consider it advisable to analyze the activities of corporate training centers as a pedagogical phenomenon, according to the following logically constructed algorithm (Figure 2).

Assessment of the effectiveness of the corporate training center for business can be done by influencing the business (i.e. achieving the goals set before the corporation); adjusting to business processes (ability to make operational changes and improvements by taking into account business development); ensuring effectiveness of training (reducing costs through innovative combination of education and methods of organization and conducting training, as well as through continuous optimization of training costs); and implementation and support of graduation business projects focused on corporation technology.

The criteria for effectiveness of the corporate training center may include: increase in sales and revenues of the company; cost reduction, including through unification of management processes or introduction of unified technologies; increase in customer satisfaction; improvement in quality of products and services; optimization of order cycle time; waste reduction; improvement in safety performance; increasing employee satisfaction; and reduction in employee turnover.

Rather, the priorities of corporate training centers are to meet the widespread shortage of mid-level managers and to establish a new management culture at a TNC. This is the key to qualitative changes, without which strategic development and success are impossible. 


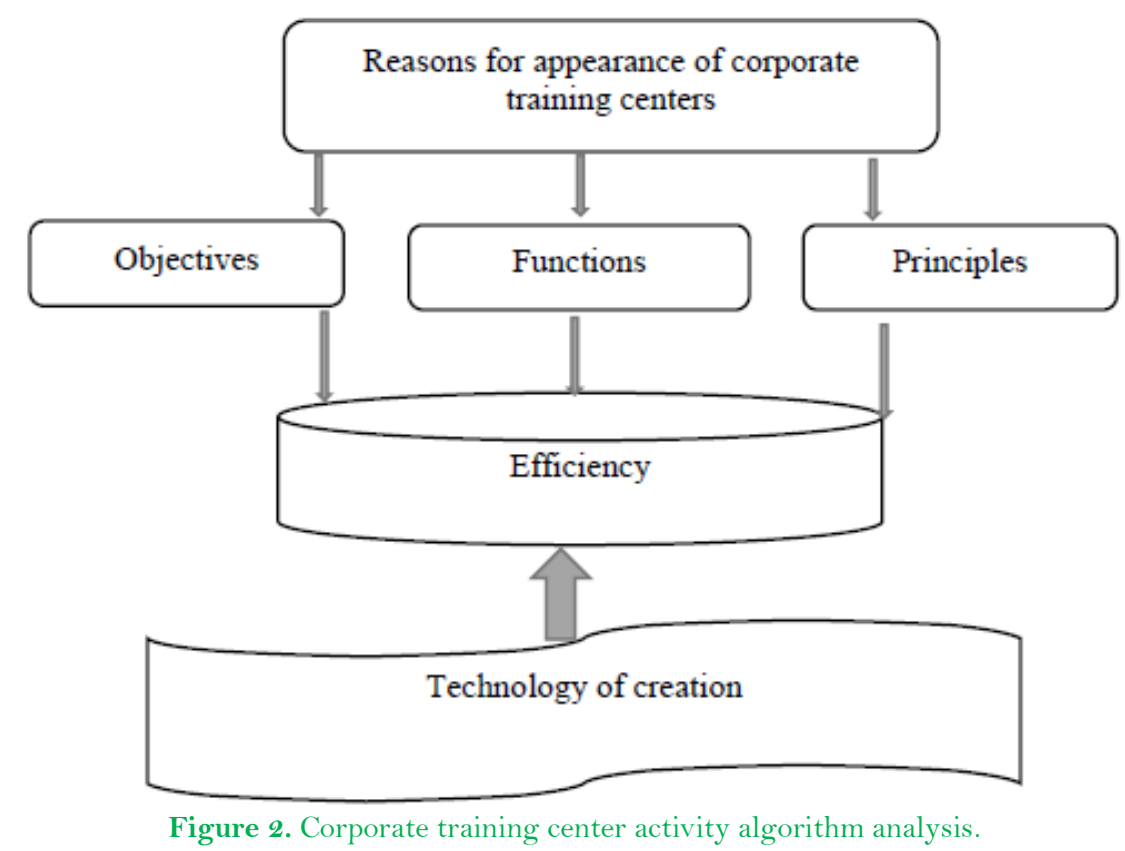

As can be seen, all of the above components are interconnected and mutually reinforcing. This is explained by the fact that a corporate training center in the modern sense is a system of in-house training and personnel development that is inextricably linked with the development strategy of the organization. It should be emphasized that the basis of any corporate training center, like all traditional universities, is a systematic approach to the learning process. However, the reasons for their evolution are different: the former resulted from the need for knowledge of the world, systematization, and transfer of knowledge while the latter resulted from acceleration of the pace of life and the need to adjust to the constant expansion of scientific and technological progress, although the prerogative of both is education itself.

Accordingly, there are two main trends in the existing programs that can be identified: "customized" programs intended exclusively for company employees (a closed system), and "special purpose" programs open to employees of other companies (an open system).

The first type of program focuses not only on educational goals related to the provision of specific knowledgerelevant knowledge, but also on their integration. In such programs, much more importance is attached to acquired knowledge that is consistent with the strategic goals of the company. Often, increasing the intrinsic motivation and identification with the company is included in the course, which enables the creation of personnel with a high level of intra-group cohesion.

The second type is experience oriented. The company that wants to distribute this organizes programs (usually certified) where knowledge on a specific topic is available to all interested parties. The first option has become more widespread because it is the cheapest and easiest way to create an in-house training center.

However, it should be emphasized that since the idea of corporate training centers began to appear in personnel departments of different organizations, their model of functioning has now changed significantly. Initially, these were development centers located in large departments and, over time, they became autonomous centers for the creation of new ideas and concepts and initiation of changes.

Starting from the essence of the corporate training center, which is to create an internal corporate knowledge system, an educational process should be directed by the company and as many internal specialists as possible should participate (as trainers). An educational alliance with commercial and government institutions is usually not limited to the provision of textbooks and premises to the company. Outside training companies or other training providers are then required to provide the company with a standard set of training methods aimed at developing and expanding standard competencies.

Identification, formalization, and the spread of unique competencies possessed by a TNC should be carried out by the company itself.

Therefore, the main idea of a corporate training center is to create an in-house system of knowledge. That is why the training process should be coordinated by the company and its internal specialists (as trainers) should participate in it. However, cooperation of an educational institution and the company should always be based on mutual enrichment of knowledge. Those profile specialists of the company who will conduct training and classes and transfer knowledge and experience to the next generation will receive the approved training method; and educational institutions, in exchange for knowledge, will provide the premises, gaining access to information accumulated by the company.

Although interaction with traditional educational institutions is a good option for employee training, the formation of independent educational structures within the company itself has become increasingly popular in recent years. If a company has many training programs for different categories of employee, if training and development programs are repeated and massive, if the proportion of unique training programs is large and their relationship to the achievement of strategic goals is obvious, then the focus should be on creating an independent educational structure with in-house trainers and training specialists. There are now separate corporate training centers that are considered independent business entities and have educational licenses (such as Global Learning, created by IBM). After studying at such a corporate university, students are issued certificates.

Due to the changes taking place in all spheres of public life, the emphasis on the issues of training and professional development of employees and their professional development is transferred from the national to the institutional. Accordingly, the important issue is to create, on the one hand, an effective system of training and professional development and, on the other, an in-house system of methodical work. 
We proceed from the traditional understanding of methodological support as a professional interaction of the subjects of pedagogical activity, which covers methodological support (curricula, programs, educationalmethodical, normative, special literature, manuals, reference books, working materials, methodological recommendations, etc.) and envisages continuous interconnection of all subjects of the educational process, taking into account the dynamics of professional development of specialists and a flexible response to this process through control and corrective procedures.

We summarize a number of the components of scientific and methodological support for in-company training and professional development of managers in TNCs in Figure 3.

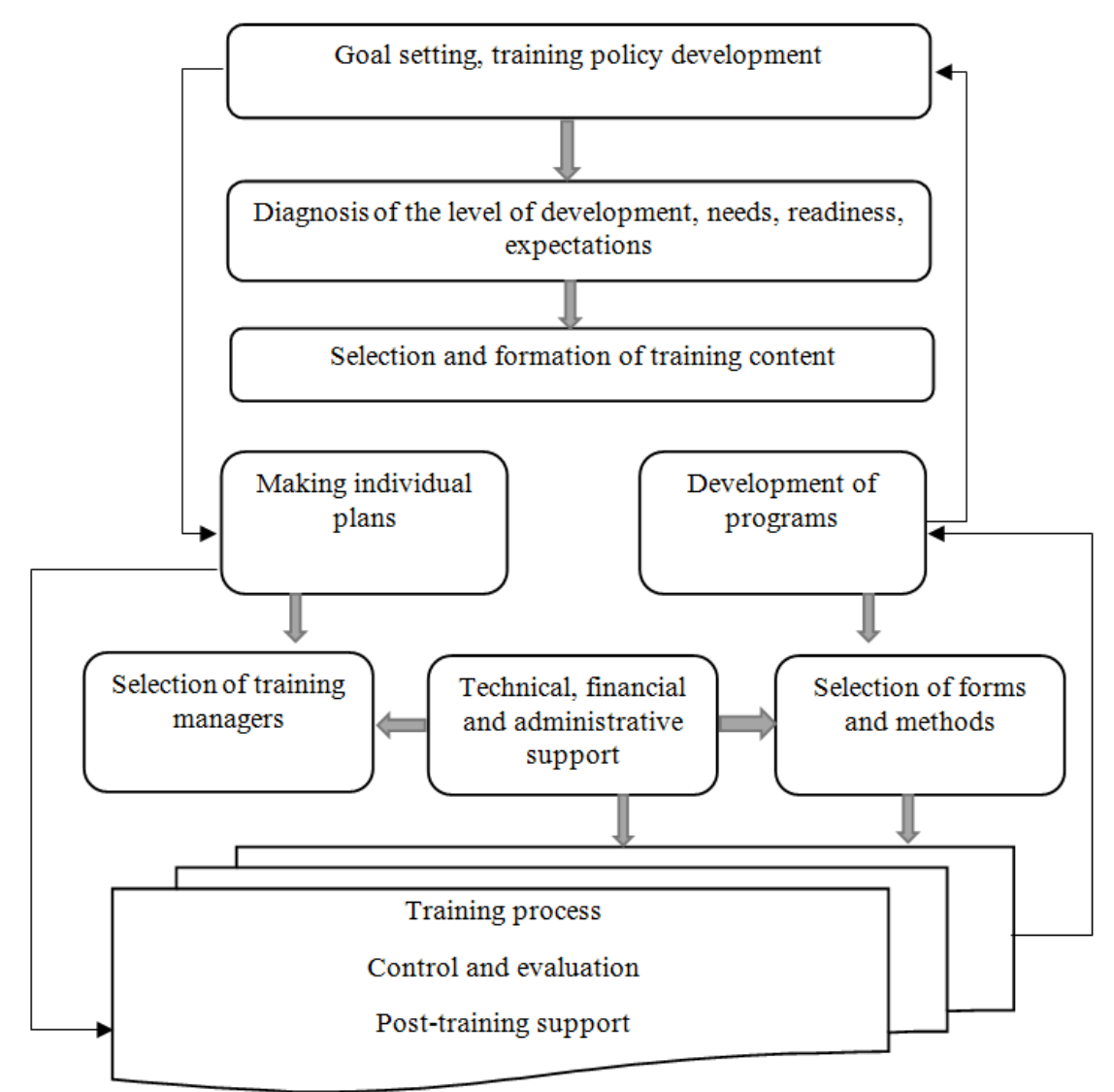

Figure 3. Components of in-house managers' training system.

Considering the subject of our research, let us dwell on the individual components. In particular, in this section we will analyze theoretical foundations of the program and methodological support for professional development of managers in TNCs, in the following forms and methods of training; then we will illustrate the system of the program and methodological support of in-company training of managers on specific cases from German and Polish TNCs. There are two main types of TNC education program: cost-effectiveness criteria that characterize the program's contribution to the economic development of TNC as a whole, including both direct and indirect effects; and social performance criteria that take into account the expected contribution of the program to social development, the indicators of which cannot be expressed in the cost estimate.

The following two types of in-house training program can be distinguished: the first is focused on enhancing external adaptation, the second on internal integration. These can be specified thematically:

1. Specialized training programs in the areas of TNC activities (training on sales, negotiations, etc.).

2. Team-building programs (active group and intergroup activities with subsequent reflection, business and role play, and problem analysis).

3. Programs for the development of interpersonal and intercompany communication and the formation of conflict management skills (sensitivity training, role-playing games, and imitation business games).

4. Corporate culture development programs.

5. Management training programs (lectures, seminars, practical classes, and educational business games).

6. Organizational innovation preparation programs (organizational mind games, project development, and organization situation analysis).

In general, researchers' views on the classification of training programs for managers are conditionally reduced to two groups: skills-training programs and personnel development programs. The content of the programs in the first group is familiarization with job responsibilities and job relationships; the sequence and methods of their implementation, priorities, target settings, familiarization with the structure of the organization and understanding its activities; official requirements and unwritten rules for mastering the necessary life skills, including selfmanagement skills; a creative approach to problem solving, career planning and review, economic skills, conflict resolution, as well as mastering computer technologies. Accordingly, selection of training programs and advanced training for managers is carried out from the perspective of training tasks (job promotion, changing job requirements, poor performance of duties, etc.).

Polish and German personnel development programs, a thorough analysis of which is presented in the following sections, also provide training that goes beyond the requirements of current job responsibilities and is accompanied by personal growth, personal and professional development, self-esteem, motivation, communication skills and maintaining relationships in the team, and enriching the employee with conceptual knowledge. This provides grounds for highlighting the following thematic areas: linear programs that contain the minimum information needed by the employee at his/her workplace; selective programs (focused training programs) that are strategic in nature and are intended only for a certain contingent of professionals with creative potential, with 
which the company invests its hopes for the future development; and development programs that are pursued by those who wish to develop and improve their skills. However, the knowledge and skills acquired during this training are not necessary today to fulfill their job duties. Such programs are more of a backup nature, enhancing the general qualification and educational level of personnel, and also play a purely social role, creating conditions for the development and expression of employees. As practice shows, German and Polish TNCs often implement projects, comprising representatives of various structural units. Theoretically, they will work on the same project and, at first glance, it would be advisable to bring them together to conduct unified training in order to save money. However, this training may not always be effective, as representatives of different units play different roles in the project and it is extremely difficult to combine them all in one training event. As a result, the investment and effort will be fruitless. For this reason, the right target audience is an important prerequisite for effective learning. In our case, the target audience is the largest possible group of managers, united by common traits that affect a particular business process and the desired results.

\section{Discussion}

Expanding a company can lead to an increase in the number of training programs in different units. On the one hand, their content may be redundant and, on the other, contradictory. In this case, organization of training requires a lot of time and effort from each unit, and searching for a training manager who reveals and promotes the culture of the organization is extremely difficult.

In such a situation TNCs increasingly decide to focus training activities of employees at all levels in an integrated program developed by the parent company. This allows not only the achievement of a universal or identical level of competency at a certain level of hierarchy or in a specific area of the organization, but also better monitoring of the dynamics of the participants, offering progressively higher levels of education and career.

However, in our opinion, the main reason why major corporations spend money on building a corporate university is to introduce continuous improvement mechanisms in the company, to increase the return on project transformation and, in the context of our research - that is, directly for managers - to promote personal and professional development throughout life.

In addition to the above, we can provide some supporting reasons: interest of the corporation's management in the strategic development of the company; the need for innovative and resourceful employees; the need not only to acquire new knowledge from the outside, but also to transfer it together with one's own experience in all branches and offices in different cities or countries, to maximize the effect of training; and the need to train personnel not only to solve pressing issues, but also to achieve medium- and long-term goals.

Rather, the primary purpose of creating a corporate training center is to provide systematic strategic personnel training - that is, training that enables the company to both solve and achieve strategic goals. It follows that the corporate training center should influence the competitiveness of a TNC, assist in implementation of its long-term strategy, and plan its work in accordance with a single ideology that follows from the company's basic strategy for the future.

The need for organizational changes and changes in the principles of personnel development management under the conditions of increasing competitive struggle implies an increase in personnel labor productivity, quality of goods, improvement in customer service, and creative and innovative attitude to the business. But first, management must be aware of the benefits of corporate training, including the following: the creation and improvement of the system of experience transfer within the company; preparation of focused specialists of a specific area of activity (cleaning, working with software products); continuous, advanced training of all employees; spread of best practices of divisions within the company; reduction in the number of errors by thoroughly reviewing the procedures of current activity; reducing the cost of expensive external training (with a welldeveloped corporate training system, it is feasible to send 1-2 employees who will pass on their knowledge to colleagues), etc.

It should be emphasized that these are not the only benefits of corporate training. Many problems can be solved using a variety of low-budget methods of internal learning; through development of intangible factors to encourage mentors, coaches, and training project managers and the use of competitive schemes between structural units during training; development of criteria and methods of evaluation of the effectiveness of training by branch; evaluation of a training program in post-program support by coaches and managers (teachers); explanatory team work; and organizational culture development, focused on development of the corporate education system.

Analysis of activities of well-known TNCs in the organization of personnel training enables us to determine under what conditions the training system works. The most important among these are the following: when there is a close relationship with the company strategy, its goals, objectives, and mission; there is a real - and not farfetched - need for training: personnel experience "pseudo-education"; formed motivation: to study fruitfully, the desire of a single manager is not enough - motivation of employees is required; the company has created a training environment and there is a positive internal PR for training; there is support from the company management at various levels; an environment is created for implementation (application), consolidation, and continuous updating of knowledge; a knowledge bank is created, enabling regular knowledge updating; and the training process is systematic and continuous.

\section{Conclusion}

Summarizing the above, let us briefly review the benefits of an in-house training organization and professional development of managers in corporate training centers. The most important things that managers receive while undergoing in-company training are: professional knowledge of the highest grade; a broad view of business problems and the ability to think systematically; experience (including experience in an intercultural environment); high level of understanding and trust (complementary team); and meeting the need for self-development and recognition. Consequently, a manager masters an innovative way of thinking about strategic development of the organization while forming their own development potential. The main directions and forms of professional development of managers within corporate training centers may include: in-company training, distance learning 
using a computer network, participation in open seminars and conferences, internships in company units, project management, mentoring, coaching, etc.

Scientific and methodological support, as a professional interaction of the subjects of pedagogical activity, involves consideration of the dynamics of professional development of specialists and constant interconnection of all subjects in the educational process. The components of scientific and methodological support in the professional development of managers in TNCs are: defining goals and developing training policies; diagnostics of the existing level of personnel development, diagnostics of the need and readiness for training, and identification of expectations; selection and formation of training content; elaboration of individual training and development plans; coordination of individual plans and elaboration of the general corporate training plan; elaboration of training and development programs; selection of types, forms, and methods of training; selection of training managers; technical, financial, and administrative support; conducting training; post-study support (implementation of acquired knowledge, adaptation of new knowledge to real-life practices); a system for monitoring, tracking changes, and evaluating the effectiveness of training and identifying gaps, which is diagnostics at a new level at the same time; adjusting training plans and programs; and personnel motivation.

The study does not exhaust the problem of professional development of managers in transnational corporations. Issues of cross-cultural training of managers in the corporate education system and training of andragogs (training managers, instructors, coaches, tutors, etc.) for effective activity in corporate training centers remain relevant. Perspective directions for further research also include theoretical-methodological and didactic substantiation of talent management and the development of their creative potential; development of tools for the stimulation and retention of managers who have received training; and the study of foreign experience in the development of leadership potential of an individual. The problem of forming ethical behavior among managers as a set of actions, and social responsibility of management at the international level, deserves special mention.

\section{References}

Akinbola, O., Solomon, K., \& Ibidunni, S. (2018). Moderating influence of corporate social responsibility on organizational performance of brewing transnational corporation. International Journal of Data and Network Science, 2(2), 49-56.

Avidov-Ungar, O., \& Reingold, R. (2018). Israeli Ministry of Education's district managers' and superintendents' role as educational leaders-implementing the new policy for teachers' professional development. International Journal of Leadership in Education, 21(3), 293-309.Available at: https://doi.org/10.1080/13603 124.2016.1164900.

Boiral, O., Raineri, N., \& Talbot, D. (2018). Managers' citizenship behaviors for the environment: A developmental perspective. Journal of Business Ethics, 149(2), 395-409.Available at: https://doi.org/10.1007/s 10551-016-3098-6.

Chen, Y., Xu, Y., \& Zhai, Q. (2019). The knowledge management functions of corporate university and their evolution: Case studies of two Chinese corporate universities. Journal of Knowledge Management, 23(10), 2086-2112.Available at: https://doi.org/10.1108/JKM04-2018-0228.

Choi, E. H., Kim, E.-K., \& Kim, P. B. (2018). Effects of the educational leadership of nursing unit managers on team effectiveness: Mediating effects of organizational communication. Asian Nursing Research, 12(2), 99-105.Available at: https://doi.org/10.1016/j.anr.2018.03.001.

Da COSTA, F. R., Pelissari, A. S., \& Gonzalez, I. V. (2018). Corporate image of public higher education institutions: Relevant factors to distance learning students. Turkish Online Journal of Distance Education, 19(1), 117-135.

Deering, D., \& Sá, C. (2018). Do corporate management tools inevitably corrupt the soul of the university? Evidence from the implementation of responsibility center budgeting. Tertiary Education and Management, 24(2), 115-127.Available at: https://doi.org/10.1080/13583883.2017.1398779.

Drobyazko, S., Barwińska-Małajowicz, A., Ślusarczyk, B., Zavidna, L., \& Danylovych-Kropyvnytska, M. (2019). Innovative entrepreneurship models in the management system of enterprise competitiveness. Journal of Entrepreneurship Education, 22(4), 1-6.

Drobyazko, S., Okulich-Kazarin, V., Rogovyi, A., Goltvenko, O., \& Marova, S. (2019). Factors of influence on the sustainable development in the strategy management of corporations. Academy of Strategic Management Journal, 18(1), 1-5.

Garber, R. (2017). Academic-corporate engagement: Strategic and organizational best practices. Research Management Revierw, $22(1)$, 1.

Gunawan, J., Aungsuroch, Y., \& Fisher, M. L. (2018). Factors contributing to managerial competence of first-line nurse managers: A systematic review. International Journal of Nursing Practice, 24(1), e12611.

Hilorme, T., Sokolova, L., Portna, O., Lysiak, L., \& Boretskaya, N. (2019). The model of evaluation of the renewable energy resources development under conditions of efficient energy consumption. Paper presented at the Proceedings of the 33rd International Business Information Management Association Conference, IBIMA 2019: Education Excellence and Innovation Management through Vision 2020.

Hilorme, T., Tkach, K., Dorenskyi, O., Katerna, O., \& Durmanov, A. (2019). Decision making model of introducing energy-saving technologies based on the analytic hierarchy process. Journal of Management Information and Decision Sciences, 22(4), 489-494.

Jamali, D., Karam, C., \& Blowfield, M. (2017). Introduction: Corporate social responsibility in developing countries: A development-oriented approach. In Development-Oriented Corporate Social Responsibility, 2, 1-12.Available at: https://doi.org/10.1111/ijmr.12112.

Kangas, M., Kaptein, M., Huhtala, M., Lämsä, A.-M., Pihlajasaari, P., \& Feldt, T. (2018). Why do managers leave their organization? Investigating the role of ethical organizational culture in managerial turnover. Journal of Business Ethics, 153(3), $707-723$.

Milner, J., McCarthy, G., \& Milner, T. (2018). Training for the coaching leader: How organizations can support managers. Journal of Management Development, $37(2), 188-200$.

Mizikaci, F. (2019). The corporate voice of the new higher education: The private discourse of capital in California State Universities. Journal for Critical Education Policy Studies (JCEPS), 17(2), 171-203.

Padley, W., Long, J., Welyczko, N., Dowsett, D., Salter, N., Ford, K., . . Brown, J. (2019). Development of a tool to support managers in planning and evaluating staff training. Nursing Standard, 34(9), 36-41.Available at: https://doi.org/10.7748/ns.2019.e 10991.

Rubens, A., Schoenfeld, G. A., Schaffer, B. S., \& Leah, J. S. (2018). Self-awareness and leadership: Developing an individual strategic professional development plan in an MBA leadership course. The International Journal of Management Education, $16(1), 1-13$.

Zhaoqun, W., \& Haiqing, H. (2017). The relationships research among incubator control, corporate flexibility and innovation incubation performance. Science \& Technology Progress and Policy, $2017(14), 2$. 